\title{
ASPECTOS MORFOLÓGICOS DE FRUTOS, SEMENTES, PLÂNTULAS E MUDAS DE LEGUMINOSAE MIMOSOIDEAE: Anadenanthera colubrina (Vellozo) Brenan e Enterolobium contortisiliquum (Vellozo) MORONG ${ }^{1}$
}

\author{
SORAIA STÉFANE BARBOSA BARRETTO², ROBÉRIO ANASTÁCIO FERREIRA ${ }^{3}$
}

\begin{abstract}
RESUMO - O presente trabalho foi realizado com o objetivo de caracterizar morfologicamente frutos, sementes, plântulas emudas de duas espécies arbóreas da família Leguminosae Mimosoideae, de ocorrência natural no estado de Sergipe para fins taxonômicos, estudos de regeneração natural e recuperação de matas ciliares. Descreveu-se e se ilustrou as características morfológicas de angico [Anadenanthera colubrina (Vellozo) Brenan] e tamboril [Enterolobium contortisiliquum (Vellozo) Morong]. Os frutos foram coletados com auxílio de podão, em cinco árvores-matrizes, distantes no mínimo 50 m entre si. Foram realizadas avaliações das características morfométricas e morfológicas externas e internas dos frutos e sementes e externas de plântulas e mudas. A. colubrina apresenta fruto seco e deiscente, enquanto em E. contortisiliquum os frutos são secos e indeiscentes. Ambas as espécies apresentam pleurograma e são exalbuminosas. Os caracteres do embrião e a germinação epígea-fanerocotiledonar são semelhantes àqueles observados em Caesalpinioideae. Na fase de muda, a presença de nectários glandulares extraflorais situados na ráquis em A. colubrina e lenticelas em $E$. contortisiliquum são úteis para as respectivas identificações. A presença de raiz com nódulos em E. contortisiliquum e tuberosa em A. colubrina são fundamentais para a precisa identificação destas. Com os resultados obtidos, conclui-se que a morfologia interna e externa dos frutos e das sementes e a morfologia externa das plântulas e mudas permitem fazer a identificação imediata e segura, fornecendo subsídios para estudos com as espécies estudadas, seja em laboratório ou em viveiro de produção de mudas e no campo das espécies estudadas.
\end{abstract}

Termos para indexação: espécies florestais, taxonomia, dendrologia, angico, tamboril.

\section{MORPHOLOGICAL ASPECTS OF FRUITS, SEEDS AND SEEDLINGS OF THE LEGUMINOSAE MIMOSOIDEAE SPECIES: Anadenanthera colubrina (Vellozo) BRENAN AND Enterolobium contortisiliquum (Vellozo) MORONG}

\begin{abstract}
The objective of this study was to characterize the morphology of the fruits, seeds and seedlings of two tree species of the Leguminosae Mimosoideae, which grow naturally in Sergipe state, for taxonomic purposes and for studies on the natural recovery and restoration of riparian forests. The morphological characteristics of angico [Anadenanthera colubrina (Vellozo) Brenan] and tamboril [Enterolobium contortisiliquum (Vellozo) Morong] have been described and illustrated. The fruits were collected by pruning 5 donor trees, at least $50 \mathrm{~m}$ distant from each other. The morphometric and the external and internal morphological characteristics of the fruits and seeds and the external seedling and nursery plant characteristics were evaluated. A.
\end{abstract}

${ }^{1}$ Submetido em 02/08/2010. Aceito para publicação em 22/102010.

${ }^{2}$ Engenheira Florestal-Universidade Federal de Sergipe, Departamento de Ciências Florestais-Av. Marechal Rondon, S/N-Jardim Rosa Elze, CEP: 49100-000-São Cristóvão-SE. E-mail: stefanebarretto@bol.com.br
${ }^{3}$ Prof. Doutor da Universidade Federal de Sergipe, Departamento de Ciências Florestais - Av. Marechal Rondon, S/N - Jardim Rosa Elze, CEP: 49100-000 - São Cristóvão - SE. E-mail: raf@infonet.com.br 
colubrina has dry, dehiscent fruits whereas E. contortisiliquum fruits are dry and indehiscent. Both species have a pleurogram and are not albuminous. The characters of the embryo and the epigeal-phanerocotylar germination are similar to those observed in the Caesalpinioideae. In the seedlings, the presence of extrafloral glandular nectaries on the rachis in A. colubrina and lenticels in E. contortisiliquum aid in the identification. The presence of root nodules in E. contortisiliquum and a tuberous root in A. colubrina are essential for species differentiation. It is concluded that the internal and external structures of the fruits and seeds and the external morphology of the seedlings will allow quick and accurate identification, providing a basis for studies with these species in the laboratory, nursery or field.

Index terms: forest species, taxonomy, dendrology, angico, tamboril.

\section{INTRODUÇÃO}

Os estudos morfológicos de frutos, sementes, plântulas e mudas são essenciais para o reconhecimento das espécies em campo, estudos de recuperação de áreas degradadas e catalogação de espécies, porque possibilita uma identificação imediata e segura no campo. A falta de pesquisas nesta área dificulta estudos relacionados à regeneração natural, atividades silviculturais e preservação de espécies que correm risco de extinção.

Uma das maiores dificuldades encontradas pelos estudiosos de plantas silvestres é a carência de informações relacionadas à identificação das espécies, uma vez que nem sempre se encontra material botânico identificado disponível (Amaro et al., 2006).

Na família Leguminosae subfamília Mimosoideae os caracteres vegetativos e florais, nos quais o estudo sistemático de Angiospermae é fundamentalmente baseado, nem sempre são suficientes para a caracterização de alguns taxa. Por este motivo os frutos e sementes vêm sendo utilizados como caracteres decisivos, sem os quais, muitas vezes, torna-se difícil o reconhecimento de determinados gêneros. Por outro lado, observa-se que, geralmente as descrições morfológicas de tais estruturas, ou são muito amplas no nível de subfamília, ou são encontradas de formas dispersas em breves diagnoses genéricas (Lima, 1985). A identificação morfológica de plântulas também permite caracterizar famílias, gêneros e até espécies, tendo sido aplicada nos estudos de inventário florestal em regiões de clima temperado e tropical (Oliveira, 1993).

De acordo com Oliveira e Pereira (1984), o conhecimento dos caracteres morfológicos de frutos e sementes são imprescindíveis, devido a sua importância taxonômica, principalmente em locais onde se recebe tais diásporos para realização de trabalhos de análises. Esta afirmativa é corroborada por Lopes e Matheus (2008), em trabalho realizado com Dimorphandra wilsonii Rizz, onde os autores afirmam que os caracteres morfológicos são importantes, pois fornecem subsídios que facilitam o reconhecimento desta espécie, principalmente em bancos de sementes.

Tanto as características externas quanto as internas são poucos modificadas pelo ambiente, constituindo-se assim, caracteres confiáveis para identificação (Gunn, 1981). Este mesmo autor apresenta informações sobre tais caracteres, em sementes de vários gêneros de Leguminosae, que podem ser seguramente utilizadas para tal finalidade. Neste sentido, algumas espécies de Leguminosae Mimosoideae foram descritas, dentre elas: Acacia polyphyla DC. (Araújo Neto et al., 2002), Dinizia excelsa Ducke e Cedrelinga caenaeformis Ducke (Melo e Varela, 2006), Enterolobium schomburgkii Benth (Ramos e Ferraz, 2008).

Apesar de serem formadas basicamente por embrião, tecidos de reserva e envoltório, na natureza, diversos fatores contribuem para que haja desenvolvimento diferenciado dos componentes da semente, variando entre espécies e até dentro da própria espécie, através da cor, forma e tamanho (Abud et al., 2010).

Em relação ao desenvolvimento de plântulas, Oliveira (1993), relata que este estádio merece uma devida atenção, pois pode ser utilizado tanto para elucidar aspectos morfo-anatômicos das espécies, quanto favorecer o reconhecimento das espécies de determinadas regiões, em estudos ecológicos. Neste sentido, Oliveira (1999) e Oliveira (2001) apresentam informações sobre esta fase de desenvolvimento que podem ser utilizadas com grande confiabilidade para tais finalidades favorecendo o reconhecimento imediato das espécies descritas pelas 
autoras.

Deve-se considerar que a fase de muda também merece atenção em estudos taxonômicos e ecológicos das espécies em campo, pois silvicultores e viveiristas em geral, observam que um grande número de espécies pode apresentar caracteres distintos das fases adultas, como a exemplo temos a filotaxia de duas espécies estudadas por Davide e Chaves (1996), Erytrina falcata Benth. e Platycyamus regnellii Benth.- Fabaceae, que modificam-se gradualmente nos estádios de plântula e muda, apresentando protófilos iniciais opostos e simples e, posteriormente, alternos, compostos e trifoliolados (heterofilia).

Em relação às informações sobre plântulas, Araújo Neto et al. (2002) apresentam dados sobre plântulas de Acacia polyphyla DC.; Melo e Varela (2006) sobre Dinizia excelsa Ducke e Cedrelinga caenaeformis Ducke e Ramos e Ferraz (2008) sobre Enterolobium schomburgkii Benth., que podem ser seguramente empregadas para identificação taxonômica destas espécies.

As espermatófitas são representadas por dois grandes grupos no reino vegetal: as Angiospermae, que é o grupo mais representativo, tanto em número de espécies, quanto em área de dispersão; e as Gimnospermae com aproximadamente 520 espécies, distribuídas em áreas mais restritas (Kozlowski e Gunn, 1972). Dentre as Angiospermae, as Leguminosae que apresentam-se distribuídas numa ampla faixa geográfica do globo, são compostas de aproximadamente 650 gêneros, com cerca de 18.000 espécies, pertencentes a três subfamílias muito distintas entre si: Caesalpinioideae, Mimosoideae e Papilionoideae (Barroso et al., 1991).

A subfamília Caesalpinioideae é composta de cerca de 50-60 gêneros, os quais são representados em aproximadamente 2.800 espécies (Barroso et al., 1991). Segundo os autores, quase dois terços das espécies conhecidas são pertencentes aos gêneros Acacia (1.200 espécies), Mimosa (400-500 espécies) e Inga (350400 espécies). Dentre as espécies de Leguminosae Mimosoideae encontram-se angico [Anadenanthera colubrina (Vellozo) Brenan] e tamboril [Enterolobium contortisiliquum (Vellozo) Morong], de ocorrência natural no estado de Sergipe, muito observadas em áreas marginais tanto em pequenos como médios e grandes cursos d’água.

Considerando-se à carência de informações quanto às características morfológicas destas espécies, este trabalho foi realizado com objetivo de caracterizar morfologicamente frutos, sementes, plântulas e mudas de angico [Anadenanthera colubrina (Vellozo) Brenan] e tamboril [Enterolobium contortisiliquum (Vellozo) Morong] para fins taxonômicos e estudos de regeneração natural, facilitando o entendimento sobre a ecologia destas espécies.

\section{MATERIAL E MÉTODOS}

Coleta de frutos e sementes - Os frutos de tamboril [E. contortisiliquum (Vellozo) Morong] foram coletados nos municípios de Santana do Francisco (situado a $10^{\circ} 18^{\prime} 01^{\prime \prime} \mathrm{S}$ e $36^{\circ} 40^{\prime} 55^{\prime \prime} \mathrm{W}$ ) e angico [A. colubrina (Vellozo) Brenan] no município de Aracaju (1054'15" $\mathrm{S}$ e $37^{\circ} 02^{\prime} 40^{\prime} \mathrm{W}$ ), diretamente de cinco árvores-matrizes, distantes no mínimo $50 \mathrm{~m}$ entre si, com auxílio de podão e lona plástica.

Secagem, beneficiamento e armazenamento das sementes - A secagem dos frutos foi realizada à sombra, por um período de 48 horas, favorecendo a abertura espontânea em A. colubrina. Em E. contortisiliquum, posterior à secagem, os frutos foram quebrados com auxílio de martelo de borracha. O beneficiamento foi realizado manualmente por debulhamento em A. colubrina e por quebra e remoção das sementes em $E$. contortisiliquum. Após a extração das sementes, foram acondicionadas em sacos plásticos impermeáveis transparentes e mantidas em câmara de armazenamento do Departamento de Ciências Florestais, da Universidade Federal de Sergipe (UFS), com temperatura e umidade controladas $\left(6\right.$ a $9{ }^{\circ} \mathrm{C}$ e 60 a $65 \%$ de umidade relativa do ar), até a produção das plântulas e mudas para a caracterização morfológica.

Caracterização morfológica de frutos e sementes: Foram realizadas, inicialmente, avaliações das características morfométricas dos frutos e das sementes (comprimento, largura e espessura) a partir de uma amostra aleatória de 100 frutos e 100 sementes de cada espécie.

$\mathrm{Na}$ caracterização dos frutos foram considerados os seguintes aspectos: tipo, coloração, dimensões, textura e consistência do pericarpo, deiscência e número de sementes por fruto.

Para as sementes, os aspectos externos observados e descritos foram: coloração, textura e consistência do tegumento, forma e bordo; posição do hilo, da micrópila e da rafe. Os aspectos internos foram: cotilédones, eixo hipocótilo-radícula e plúmula. As sementes foram hidratadas para facilitar o estudo da morfologia interna. 
As observações foram feitas com auxílio de microscópio estereoscópico bilocular (4x). As medidas de comprimento, largura e espessura dos frutos e sementes foram obtidas com paquímetro digital (Digimess), obtendo-se assim as medidas mínimas, médias e máximas.

Os métodos e os termos empregados foram baseados nos trabalhos de Beltrati (1992); Damião-Filho (1993); Vidal e Vidal (1995), Barroso et al. (1999) e Ferreira et al. (2001).

Caracterização morfológica de plântulas e mudas: Para o acompanhamento do desenvolvimento de plântulas e mudas, foram produzidos 100 indivíduos de cada espécie. Para a caracterização das plântulas, as sementes foram semeadas em bandejas de polietileno (40x30x8 $\mathrm{cm}$ ), contendo como substrato areia (lavada, peneirada e esterilizada em estufa com circulação de ar a $120{ }^{\circ} \mathrm{C}$ durante 24 horas). As sementes foram semeadas sobre substrato e mantidas em germinador tipo Mangelsdorf, com a temperatura constante de $25{ }^{\circ} \mathrm{C}$, sob luz contínua. Para mantê-las hidratadas, foi feita a reposição de água sempre que necessário. A sala de germinação foi climatizada, mantendo a temperatura ambiente em $28{ }^{\circ} \mathrm{C}$ $\pm 2{ }^{\circ} \mathrm{C}$. Para evitar a infestação por microrganismos, as sementes foram tratadas com água sanitária $2 \%$ durante dois minutos, seguida de lavagem em água destilada.

As avaliações foram realizadas a cada dois dias, sendo consideradas germinadas as plântulas que apresentaram todas as estruturas essenciais normais (raiz primária, hipocótilo, cotilédones, epicótilo e protófilos abertos). Para acelerar a germinação, as sementes de $E$. contortisiliquum foram lixadas com lixa $n^{0} 50$ do lado oposto da micrópila. Em A. colubrina não foi empregado tratamento pré-germinativo.

O estádio de plântula foi considerado quando os protófilos já estavam totalmente formados e o de muda, a partir do surgimento do $2^{\circ}$ protófilo. As mudas foram produzidas no Viveiro Florestal do Departamento de Ciências Florestais/UFS. Como recipiente foi utilizado saco de polietileno preto $(14 \times 25 \mathrm{~cm})$, tendo como substrato terra de subsolo, areia e esterco de curral curtido, na proporção 3:1:1. A adubação inicial foi realizada com 5,0 kg de superfosfato simples +500 g de cloreto de potássio + 300 g de micronutrientes (FTE ${ }^{\circledR}$ - BR12 - Fritted Trace Elements) para cada $\mathrm{m}^{3}$ de substrato e, a de cobertura a partir de 30 dias após a emergência, utilizando-se $60 \mathrm{~g}$ de cloreto de potássio +25 g de sulfato de amônio diluído em $10 \mathrm{~L}$ de água, segundo as recomendações sugeridas por Faria (1999).
Os elementos vegetativos descritos e ilustrados foram os mesmos sugeridos por Roderjan (1983): raiz (principal e secundária), colo, hipocótilo, cotilédones, epicótilo, protófilos de $1^{\underline{a}}$ ordem, caule jovem e protófilos de $2^{\underline{a}}$ ordem. Os termos empregados para estas fases estão de acordo com os trabalhos de Oliveira (1993); Barroso et al. (1999) e Ferreira et al. (2001). Todas as fases descritas foram fotografadas com máquina digital.

\section{RESULTADOS E DISCUSSÃO}

\section{Angico, angico-vermelho, angico-preto [Anadenanthera colubrina (Vellozo) Brenan] \\ Caracterização morfológica do fruto (Figura}

1): O fruto é do tipo folículo, simples, seco, deiscente, polispérmico (variando de 9 a 14 sementes), glabro, de formato linear-ondulado. O comprimento médio é de $29,75 \mathrm{~cm}$ (variando de 13,5 a 39,5 cm), largura média de 2,26 cm (variando de 2,03 a 2,44 cm) e espessura média de $0,34 \mathrm{~cm}$ (variando de 0,16 a $0,46 \mathrm{~cm}$ ). O epicarpo é seco, opaco, marrom-claro, evidenciando os lóculos, onde estão alojadas as sementes; há presença de estrias no centro de cada lóculo, apresentando bordo mais espesso que o centro do fruto e reentrâncias onduladas em todo seu comprimento; base acuminada, bordo bastante ondulado, estipitado, com pedúnculo lenhoso, marrom e estriado verticalmente; apresenta diversas lenticelas circulares e de coloração amarelada; mesocarpo seco, amarelado, e endocarpo apresenta-se seco, de coloração alaranjada, formando falsos septos onde são alojadas as sementes.

Caracterização morfológica das sementes (Figuras 2 e 3): As sementes são estenospérmicas, com formato variando de arredondada a reniforme; a testa é rugosa, coriácea, glabra, de coloração marrom, altamente polida, com presença de estrias e ondulações; o comprimento médio é de 1,29 $\mathrm{cm} \pm 0,096$ (variando de 1,04 a 1,50 cm), largura média de $1,37 \mathrm{~cm} \pm 0,117$ (variando de 1,04 a $1,60 \mathrm{~cm}$ ) e espessura média de $0,09 \mathrm{~cm} \pm 0,02$ (variando de 0,02 a $0,13 \mathrm{~cm}$ ). Apresenta uma reentrância na região hilar, sendo o hilo e a micrópila circulares, basais e homócromos, visíveis a olho nu. Na testa observa-se o pleurograma aberto, próximo à base da semente e com a abertura em sua direção. O funículo é diminuto, de coloração amarelada. Os cotilédones são carnosos, de coloração marrom-conhaque, variando entre oblongo e reniforme; a base é cordiforme, apresentando uma fenda quando os lobos estão superpostos; o ápice é arredondado. 
Embrião reto, axial, invaginado, devido a sua espessura bastante fina; o eixo-embrionário pode ser visualizado a olho nu sem hidratar a semente. Eixo hipocótilo-radícula é cilíndrico, invaginado, curto, reto e não ultrapassa os cotilédones. A plúmula é bem visível, com protófilos formados, bem definidos e delimitados.

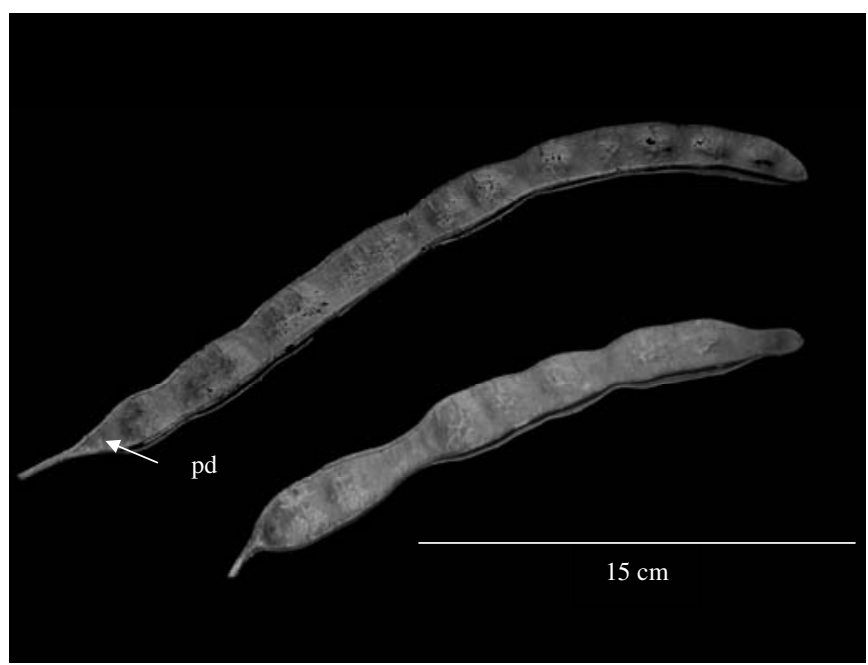

FIGURA 1. Aspectos da morfologia externa do fruto de angico [Anadenanthera colubrina (Vellozo) Brenan]. Legenda: pd - pedúnculo.

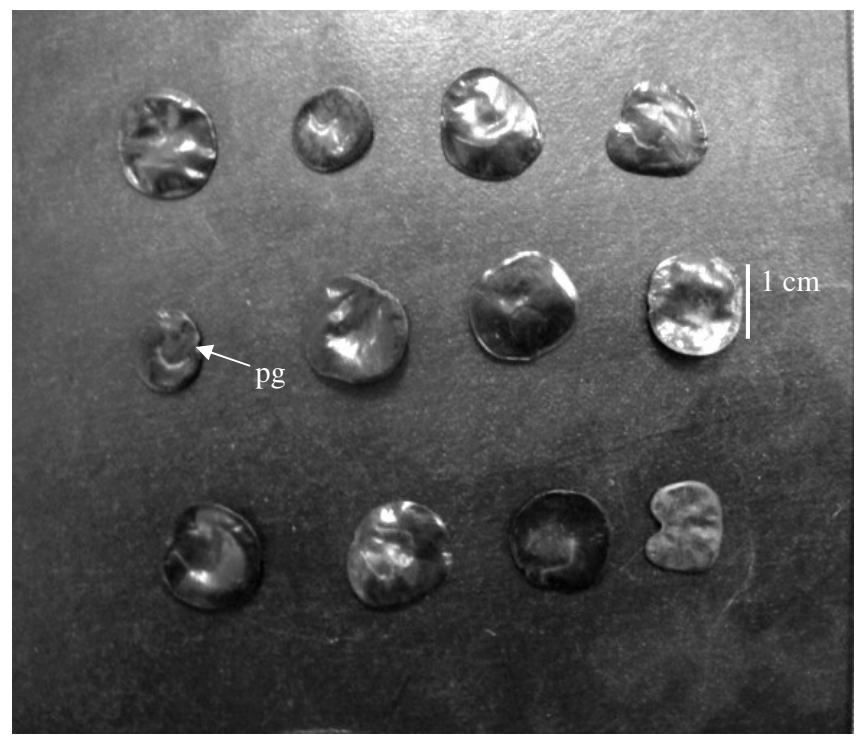

FIGURA2. Aspectos da morfologia externa de sementes de angico [Anadenanthera colubrina (Vellozo) Brenan]. A - Detalhe da forma e da rugosidade das sementes. Legenda: pg pleurograma.

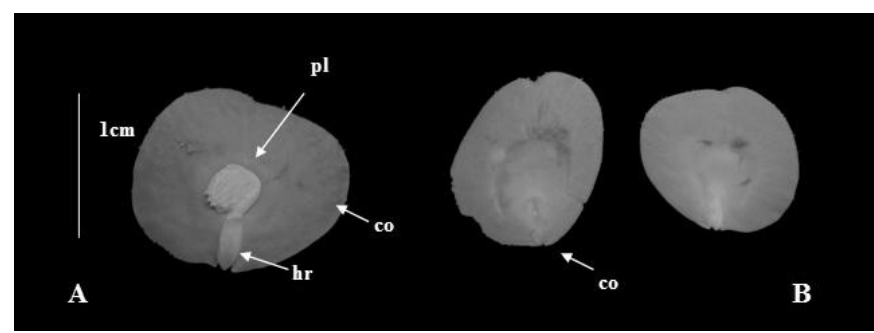

FIGURA3. Aspectos da morfologiainterna de sementes de angico [Anadenanthera colubrina (Vellozo) Brenan]. A - Embrião aberto, mostrando cotilédone e plúmula bem definida com os protófilos (pl) e eixo hipocótilo-radícula (hr). B - detalhe dos cotilédones abertos (co). Legenda: co - cotilédone; hr - eixo hipocótilo-radícula; pl-plúmula.

Caracterização morfológica da plântula (Figura 4): Com o intumescimento da semente, no inicio da germinação, há ruptura do tegumento na região da micrópila. No primeiro dia ocorre a protrusão da radícula, fina, cônica e de coloração branca. Com o desprendimento do tegumento, surgem os cotilédones de coloração amarelada e forma circular; estes se abrem presos ou não ao tegumento, mostrando os protófilos fechados; gradativamente vai surgindo o epicótilo, brilhoso e de coloração verde-clara; consequentemente, abrem-se os protófilos e, no sexto dia, a plântula está completamente formada. A germinação é do tipo epígea-fanerocotiledonar.

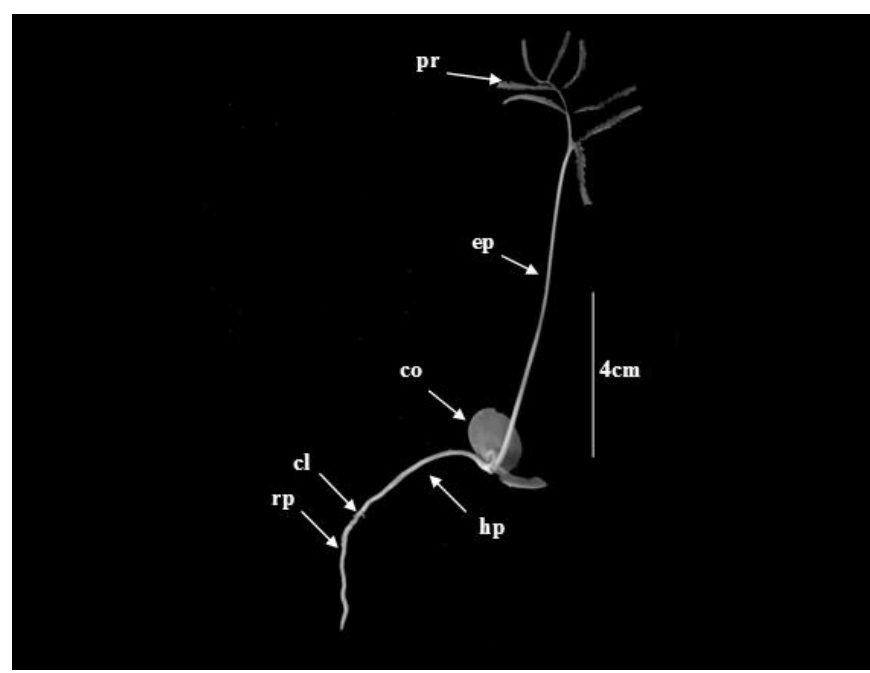

FIGURA 4. Aspectos morfológicos externos da plântula de angico [Anadenanthera colubrina (Vellozo) Brenan]. Legenda: cl - coleto; co - cotilédone; ep - epicótilo; hp - hipocótilo; pr-protófilos; rp - raiz primária. 
A plântula apresenta raiz pivotante, glabra, tortuosa ou não, de coloração parda-amarelada, cilíndrica, com comprimento variando de 1,88 a 2,16 cm e diâmetro de 0,10 a $0,13 \mathrm{~cm}$. O coleto apresenta coloração branca, com diâmetro variando de 0,16 a $0,20 \mathrm{~cm}$. O hipocótilo é cilíndrico, com leve tortuosidade, de coloração brancoamarelada; consistência membranácea com comprimento variando de 0,64 a 0,67 cm. Cotilédones reniformes, ápice retuso, base sagitada com uma reentrância; são carnosos, amarelados, com comprimento variando de 1,48 a 1,70 cm e largura de 1,57 a 0,16 cm. Epicótilo levemente curvado ou não, cilíndrico, glabro, de coloração verdeclara, consistência herbácea, com comprimento variando de 6,53 a $8,70 \mathrm{~cm}$. As folhas são compostas com 4 pares de folíolos discolores (verde-escuros na face adaxial e verde-claros na face abaxial); consistência membranácea, com comprimento variando entre 1,89 a 2,42 cm e largura de $0,14 \mathrm{~cm}$. Folíolos terminais com comprimento variando de 1,39 a 2,12 cm; foliólulos com média de $0,15 \mathrm{~cm}$ de comprimento e 0,07 cm de largura, apresentando base arredondada, ápice agudo e bordo inteiro. Presença de ráquis com comprimento variando entre 0,41 a $0,75 \mathrm{~cm}$.

Caracterização morfológica da muda (Figura 5): Raiz principal tuberosa, tortuosa, pivotante, marromclara, com comprimento variando de 39,50 a $63,00 \mathrm{~cm}$ e diâmetro de 0,38 a $0,57 \mathrm{~cm}$; raízes secundárias com comprimento variando de 11,00 a 20,00 cm e diâmetro de 0,03 a $0,06 \mathrm{~mm}$; raízes terciárias finas, de coloração marrom-escura, com comprimento variando de 2,60 a 3,50 cm e diâmetro de 0,01 a 0,02 mm. O coleto caracteriza-se por uma faixa marrom-clara, de 0,30 a 0,41 cm de diâmetro. O caule jovem é tortuoso, com coloração marrom-escura; com presença de estrias verticais na base e lenticelas circulares, de coloração bege; é lenhoso, glabro, cilíndrico com altura variando de 2,15 a 3,20 cm e diâmetro do colo de 0,28 a $0,31 \mathrm{~cm}$. Folha recomposta, com coloração verde, com comprimento variando de 3,94 a $14,74 \mathrm{~cm}$, consistência membranácea, e com pulvino verde-claro com comprimento variando de 0,41 a 0,49 cm; cada folha apresenta 11 a 19 pares de folíolos com comprimento variando de 2,11 a 3,70 cm, paripenados, discolores (face adaxial verde-escura e face abaxial verdeclara), com pecíolo de comprimento variando de 0,97 a $1,08 \mathrm{~cm}$; coloração vermelha na face adaxial e verde-clara na abaxial; cada um dos folíolos apresenta 21 a 33 pares de foliólulos, estes com 0,31 a 0,38 cm de comprimento e largura de 0,08 a $0,10 \mathrm{~cm}$, oblongos, opostos dísticos, ápice agudo e base arredondada, com pulvino de 0,05 cm de diâmetro e 0,10 cm de comprimento; observase a presença de nectário extrafloral, de coloração avermelhada.

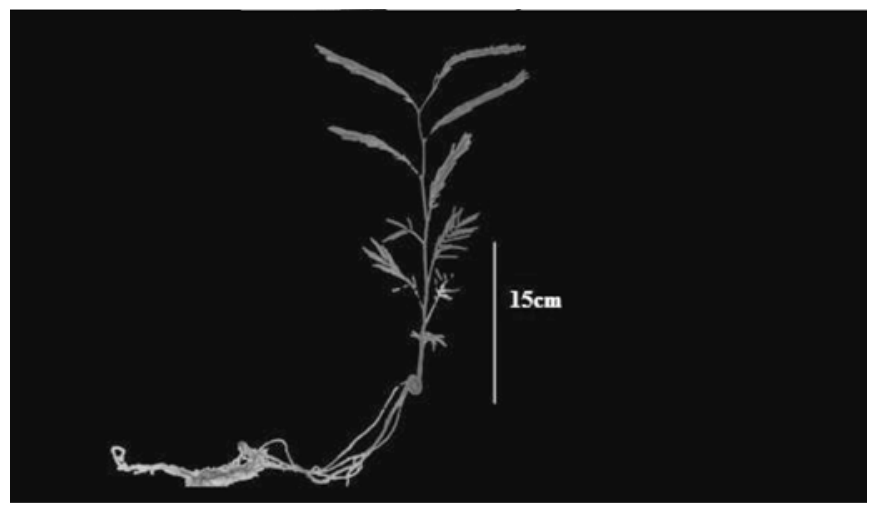

FIGURA5. Aspectos morfológicos externos da muda de angico [Anadenanthera colubrina (Vellozo) Brenan].

\section{Tamboril, orelha-de-negro e timburi [Enterolobium contortisiliquum (Vellozo) Morong] \\ Caracterização morfológica do fruto (Figura 6): O} fruto é do tipo legume bacoide, simples, seco, indeiscente, retorcido, reniforme, polispérmico (12 a 15 sementes); o comprimento médio é de 4,17 cm (variando de 2,15 a 4,79 $\mathrm{cm}$ ), largura média de 7,87 cm (variando de 5,11 a 9,18 cm) e espessura média de 1,62 cm (variando de 0,56 a 1,85 cm). O pericarpo é distinto: a) epicarpo rugoso, pouco polido a opaco, glabro, esponjoso-coriáceo, com estrias verticais, variando entre o marrom vermelho-goya a preto, apresenta ondulações ao longo do seu comprimento, evidenciando a divisão dos falsos septos; extremidade auriculiforme, bordo ondulado, estipitado, de pedúnculo lenhoso e estriado verticalmente; b) mesocarpo alvacento, esponjoso, de consistência pegajosa e de coloração amarelada e c) endocarpo branco, fibroso, formando falsos septos.

Caracterização morfológica das sementes (Figuras 7 e 8): As sementes são estenospérmicas, achatadas e oblongas; apresenta comprimento médio de $1,35 \mathrm{~cm} \pm$ 0,127 (variando de 1,05 a 1,64 cm), largura média de 0,95 $\mathrm{cm} \pm 0,093$ (variando de 0,64 a $1,10 \mathrm{~cm}$ ) e espessura média de $0,66 \mathrm{~cm} \pm 0,076$ (variando de 0,50 a $0,83 \mathrm{~cm}$ ). A testa é lisa, córnea, bicolor, glabra, pouco polida a opaca, variando entre marrom-escuro a preta. Funículo longo, amarelado e espiralado. Hilo basal, circular, heterócromo, de coloração clara. Micrópila basal, circular e de coloração clara. 
Evidencia-se a presença ou não do prolongamento da rafe; apresenta pleurograma em forma de ferradura de coloração mais escura, formando a auréola. O hilo, a micrópila e o prolongamento da rafe são visíveis a olho nu. O embrião é reto, axial e invaginado, com cotilédones de coloração creme, planos, variando a forma de acordo com a semente; apresentam consistência córnea quando secos e, carnosa quando hidratados; base cordada, com uma pequena fenda ou depressão quando os lobos estão superpostos; ápice arredondado. Eixo hipocótilo-radícula bem delimitado, curto, invaginado, reto e cilíndrico. A plúmula é visível, com formação dos protófilos.

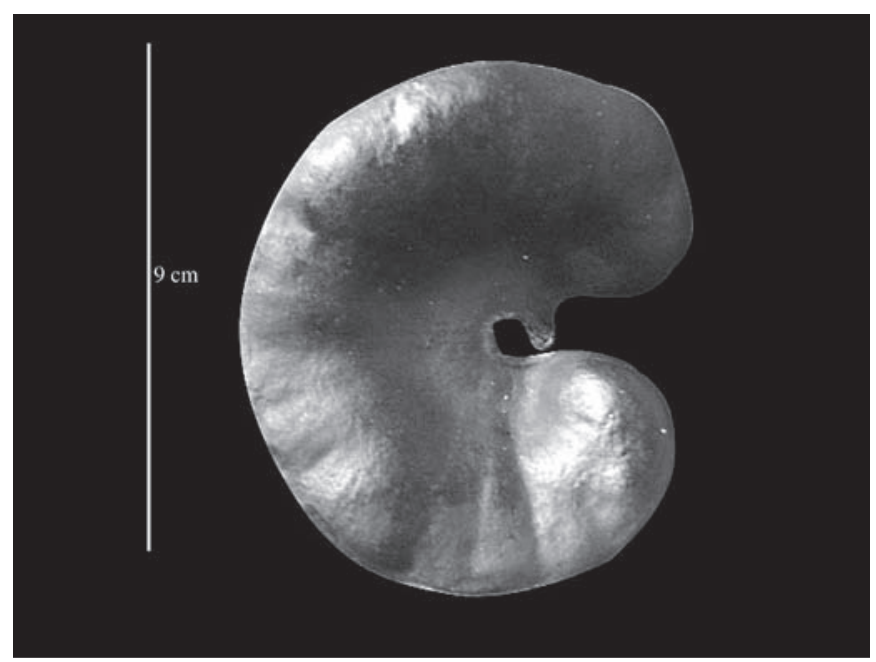

FIGURA 6. Aspectos da morfologia externa do fruto de tamboril [Enterolobium contortisiliquum (Vellozo) Morong].

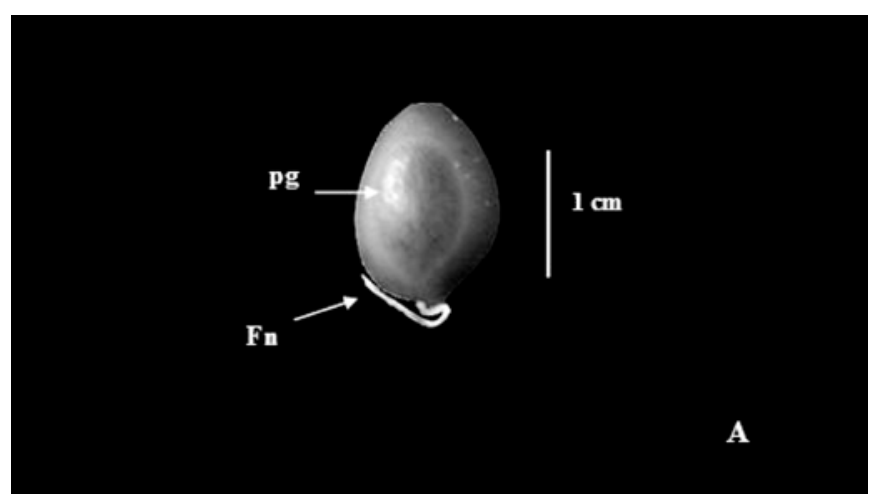

FIGURA 7. Aspectos da morfologia externa de sementes de tamboril [Enterolobium contortisiliquum (Vellozo) Morong]. Legenda: fu - funículo; pg - pleurograma.

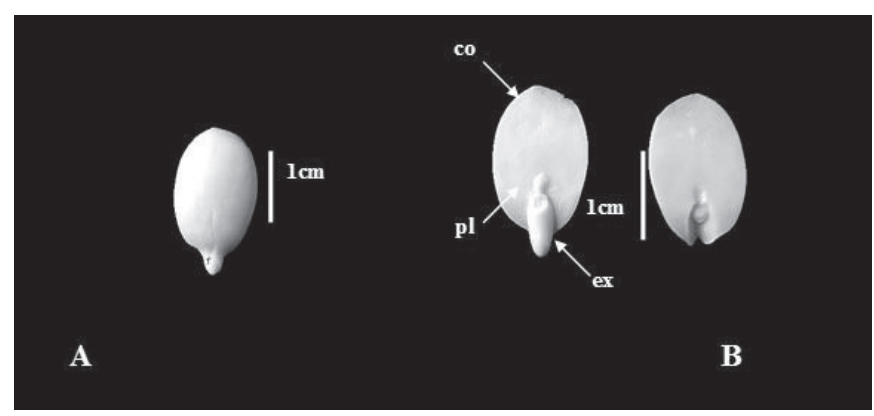

FIGURA 8. Aspectos morfológicos do embrião de tamboril [Enterolobium contortisiliquum (Vellozo) Morong.] A - Detalhe do embrião fechado. B - detalhe do embrião aberto com cotilédones e eixo-embrionário. Legenda: co - cotilédone; ex - hipocótilo-radícula e plúmula (pl).

Caracterização morfológica da plântula (Figura 9): Há o intumescimento da semente e na base o tegumento vai se rompendo, estendendo-se para as laterais. Na região da micrópila, no terceiro dia, há a protrusão da radícula, que se apresenta fina e cônica; gradativamente se alonga, surgindo o hipocótilo de coloração verde-clara e brilhoso e, à medida que cresce, há uma diferenciação da radícula, devido ao aumento da largura, com o tegumento ainda preso aos cotilédones. Com o desprendimento do tegumento, os cotilédones verdeamarelados se abrem, surgindo os protófilos; posteriormente, o epicótilo de coloração verde-clara alonga-se e, no décimo quinto dia, a plântula está completamente formada. A germinação é do tipo epígea-fanerocotiledonar.

A plântula apresenta raiz pivotante, de coloração parda, com comprimento variando de $5,70 \mathrm{~cm}$ a 5,84 $\mathrm{cm}$ e diâmetro de 0,05 a 0,14 cm. Coleto com diâmetro variando de 0,21 a 0,24 cm, verde-claro, levemente curvado e afilado. Hipocótilo verde-claro, cilíndrico, liso, glabro, ligeiramente ondulado, com comprimento variando de 10,28 cm a 14,02 cm. Cotilédones concolores (verdeescuros nas faces abaxial e adaxial), carnosos, opacos, base sagitada, ápice acuminado, bordo inteiro, forma obovada, com comprimento variando de 1,52 a 1,66 cm e largura de 0,85 a 0,89 cm. Epicótilo com altura variando de 6,91 a 7,23 $\mathrm{cm}$, verde-claro, glabro e cilíndrico. Protófilos compostos, alternos espiralados, com folíolos discolores (face adaxial verde-escura e abaxial verde-clara), ápice agudo, bordo inteiro, liso, base obtusa, formato oblongo, glabro, com comprimento variando de 0,86 a $1,00 \mathrm{~cm}$ e diâmetro de 0,31 a 0,43 cm. Pecíolos de coloração verde, com presença de estípulas e pulvino. 

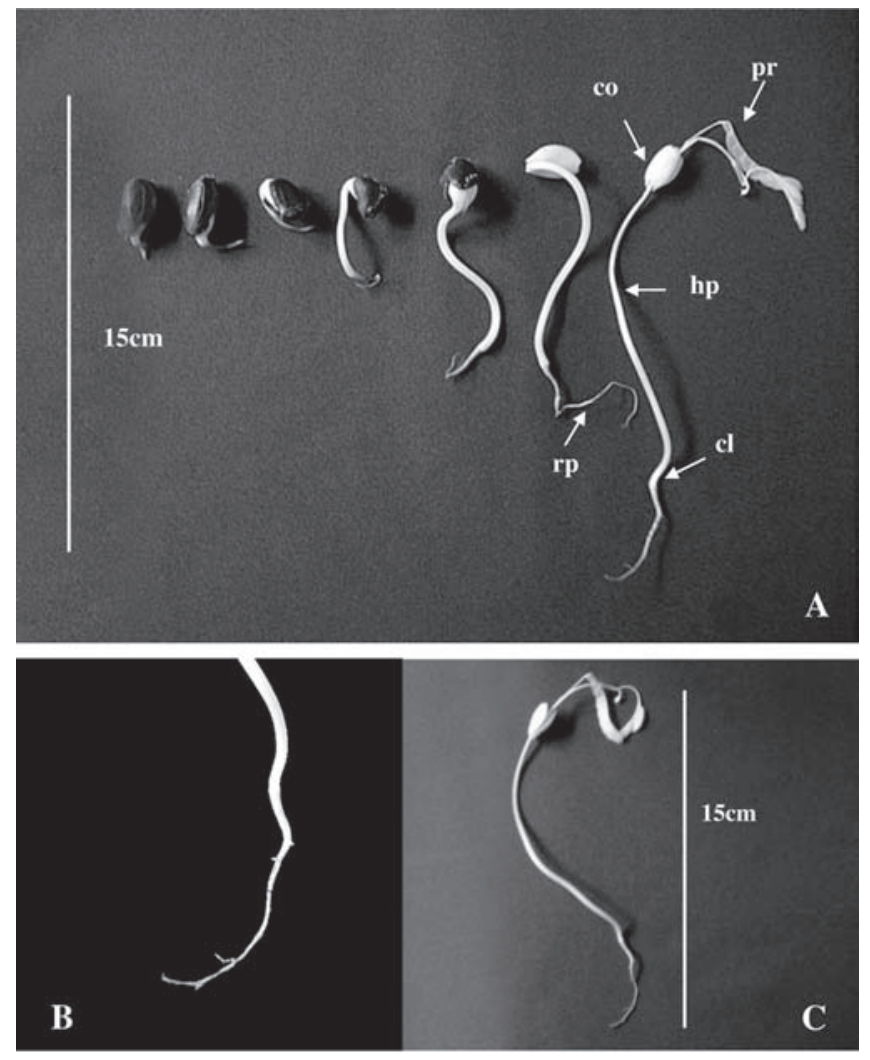

FIGURA 9. Aspectos morfológicos externos de plântulas de tamboril [Enterolobium contortisiliquum (Vellozo) Morong.].A - Germinação e plântula em desenvolvimento. B - Detalhe externo da raiz pivotante e $\mathrm{C}$ - Plântula formada. Legenda: cl-coleto; co-cotilédone; hphipocótilo; pr-protófilos; rp-raiz primária.

Caracterização morfológica da muda (Figura 10): A raiz é pivotante, com comprimento variando de 10,70 a 14,00 cm e diâmetro de 0,18 a 0,93 cm; de coloração bege, tuberosa, com presença de nódulos; as raízes secundárias apresentam comprimento variando de 4,0 a 6,7 cm e diâmetro de 0,04 a $0,11 \mathrm{~cm}$; raízes terciárias ramificadas, finas e beges, com comprimento variando de 3,29 a $8,83 \mathrm{~cm}$ e diâmetro de $0,08 \mathrm{~mm}$ a $0,53 \mathrm{~mm}$. Caule jovem cilíndrico, lenhoso, brilhoso, levemente tortuoso ou não, verdeclaro, com altura variando de 21,2 a $25,5 \mathrm{~cm}$ e diâmetro do colo de 0,33 a $0,35 \mathrm{~cm}$; apresenta-se rugoso, devido à grande quantidade de lenticelas, circulares e de coloração branca. Coleto com diâmetro variando de 0,36 a $0,51 \mathrm{~cm}$, de coloração verde-clara, com descamação esbranquiçada e estrias verticais. Folhas compostas bipinadas, alternasespiraladas, pecioladas (com comprimento variando de
2,24 a 4,53 cm e largura de 0,08 a 0,11 cm); presença de estípulas foliáceas, verde-escuras na base do pulvino, sendo este verde-escuro, glabro com comprimento variando de 2,50 a 3,00 cm. Folíolos com 4 a 9 pares de foliólulos, de comprimento variando de 1,10 a $1,46 \mathrm{~cm}$ e largura de 0,44 a $0,50 \mathrm{~cm}$, discolores (face adaxial verde-escura e abaxial verdeclara); pilosos, subsésseis, filotaxia oposta dística, consistência membranácea; nervação peninérvea; bordo inteiro, com ápice acuminado e base assimétrica; pulvínulo dos folíólulos com comprimento variando de 0,21 a $0,26 \mathrm{~cm}$.

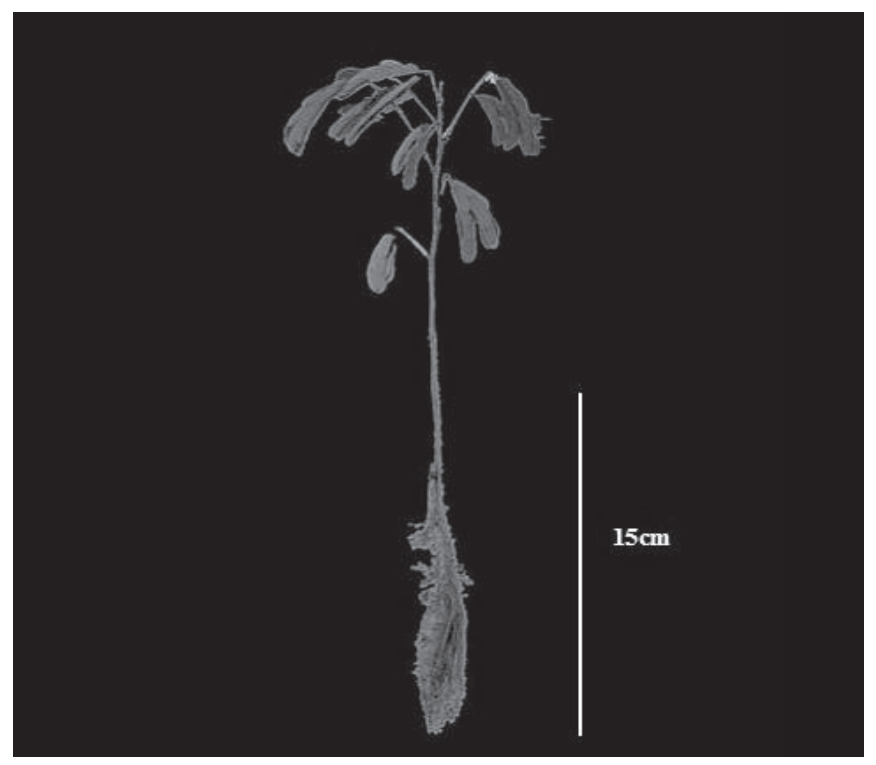

FIGURA 10. Aspectos morfológicos externos da muda de tamboril [Enterolobium contortisiliquum (Vellozo) Morong.].

Observou-se neste trabalho que as raízes de Enterolobium contortisiliquum (Vellozo) Morong, apresentaram nódulos, como também foi mencionado por Oliveira (1999). Outra característica diferenciativa foi a presença de raiz tuberosa na fase de muda em Anadenanthera colubrina (Vellozo) Brenan. Em Enterolobium contortisiliquum (Vellozo) Morong não se observa esta característica.

\section{CONCLUSÕES}

Anadenanthera colubrina (Vellozo) Brenan apresenta fruto seco e deiscente, enquanto em Enterolobium contortisiliquum (Vellozo) Brenan os frutos são secos e indeiscentes. Ambas as espécies apresentam pleurograma e são exalbuminosas. 
Caracteres do embrião (cotilédones e eixo-embrionário com plúmula definida) e a germinação do tipo epígeafanerocotiledonar são semelhantes.

$\mathrm{Na}$ fase de muda (planta jovem), há presença de nectários glandulares extraflorais na ráquis em $A$. colubrina (Vellozo) Brenan e lenticelas em E. contortisiliquum (Vellozo) Brenan. E ainda, nesta fase, a presença de raiz com nódulos em E. contortisiliquum (Vellozo) Brenan e tuberosa em A. colubrina (Vellozo) Brenan.

\section{AGRADECIMENTOS}

Este trabalho foi realizado com o apoio do Programa de Iniciação Científica da Universidade Federal de Sergipe, Coordenação de Pesquisa (CNPq/UFS/COPES) e do Banco do Nordeste do Brasil, por meio do ETENE/ FUNDECI - Projeto Revitalização do Rio São Francisco.

\section{REFERÊNCIAS}

ABUD, H.F; GONÇALVES, N.R.; REIS, R.G.E.; GALLÃO, M.I.; INNECCO, R. Morfologia de sementes e plântulas de cártamos. Revista Ciência Agronômica, v.41, n.2, p.259-265, 2010.

http://www.ccarevista.ufc.br/seer/index.php/ccarevista/ article/view/727/436

AMARO, M.S.; FILHO, S.M.; GUIMARÃES; R.M.; TEÓFILO, E.M. Morfologia de frutos, sementes e de plântulas de Janaguba (Himatanthus drasticus (MART.) PLUMEL.- (Apocynaceae). Revista Brasileira de Sementes, v.28, n.1, p.63-71, 2006.

http://www.scielo.br/pdf/rbs/v28n1/a09v28n1.pdf

ARAÚJO NETO, J.C.; AGUIAR, I.B.; FERREIRA, V.M.; PAULA, R.C. Caracterização morfológica de frutos e sementes e desenvolvimento pós-seminal de monjoleiro (Acacia polyphylla DC.). Revista Brasileira de Sementes, v.24, n.1, p.203-211, 2002. http://www.abrates.org.br/ revista/artigos/2002/v24n1/artigo29.pdf

BARROSO, G.M.; PEIXOTO, A.L.; ICHASO, C.L.F., COSTA, C.G., GUIMARÃES, E.F.; LIMA, H.C. Sistemática de Angiospermas do Brasil, 3.ed. Viçosa: UFV, 1991. 326p.

BARROSO, G.M., MORIM, M.P., PEIXOTO, A.L.; ICHASO, C.L.F. Frutos e sementes: morfologia aplicada à sistemática de dicotiledôneas. Viçosa: UFV, 1999. 443p.

BELTRATI, C.M. Morfologia e anatomia de sementes.
Rio Claro: UNESP, Dep. de Botânica/ Instituto de Biociências, 1992. 108p. (Apostila do Curso de PósGraduação).

DAMIÃO FILHO, C.F. Morfologia Vegetal. Jaboticabal: FUNEP/UNESP, 1993. 243p. http://scholar.google.com. $\mathrm{br} / \mathrm{scholar} ? \mathrm{q}=\% 20 \mathrm{Morfologia} \% 20$ Vegetal

DAVIDE, A.C; CHAVES, M. M. F. Morfologia de semente de plântula e de mudas de Erytrina Falcata Benth. E Platycyamus Regnellii Benth. - Fabaceae. Cerne. v.2, n.2, p. 69-80, 1996. http://www.dcf.ufla.br/CERNE/ revistav2n2-1996/01095.PDF

FARIA, J.M.R. Propagação de espécies florestais para recomposição de matas ciliares. In: SIMPÓSIO MATA CILIAR: CIÊNCIA E TECNOLOGIA,1., Belo Horizonte, 1999. Anais... Lavras: UFLA/FAEPE/CEMIG, 1999. p.6979.

FERREIRA, R.A.; BOTELHO, S.A.; DAVIDE, A.C.; MALAVASI, M.M. Morfologia de frutos, sementes, plântulas e mudas de Dimorphandra mollis Benth - faveira (Leguminosae Caesalpinioideae). Revista Brasileira de Botânica, v.24, n.3, p.303-309, 2001. http://www.scielo.br/ scielo.php?pid=S0100-84042001000300009\&script $=$ sci arttext\&tlng=es

GUNN, C.R. Seed topography in the Fabaceae. Seed Science \& Tecnology, v.9, n.3, p.737-757, 1981.

KOSLOWSKI, T.T.; GUNN, C.R. Importance and characteristics of seeds. In: KOSLOWSKI, T.T. Seed biology, New York: Academic Press, 1972. p.1-20.

LIMA, M.P.M. de; Morfologia dos frutos e sementes dos gêneros da tribo Mimoseae (Leguminosae- Mimosoideae) aplicada à sistemática. Rodriguésia, v.37, n.62 p.53-78, jan./jun. 1985.

LOPES, J.C.; MATHEUS, M.T. Caracterização morfológica de sementes, plântulas e da germinação de Dimorphandra wilsonii Rizz. - faveiro-de-Wilson (Fabaceae Caesalpinioideae). Revista Brasileira de Sementes, v.30, n.1, p.96-101, 2008. http://www.scielo.br/ pdf/rbs/v30n1/a13v30n1.pdf

MELO, M.D.F.F.; VARELA, V.P.; Aspectos morfológicos de frutos, sementes, germinação e plântulas de duas espécies florestais da Amazônia. I. Dinizia excelsa DUCKE (Angelim - pedra). II. Cedrelinga catenaeformis DUCKE (Cedrorana) - (Leguminosae- Mimosoideae). Revista Brasileira de Sementes, v.28, n.1, p.54-62, 2006.http:// www.scielo.br/pdf/rbs/v28n1/a08v28n1.pdf

OLIVEIRA, D.M.T. Morfo-anatomia do embrião de leguminosas arbóreas nativas. Revista Brasileira de 
Botânica, v.22, n.3, p.413-427, 1999. http://www.scielo.br/ scielo.php?pid=S0100-84041999000300010\&script $=$ sci arttext\&tlng=es

OLIVEIRA, D.M.T.; Morfologia comparada de plântulas e plantas jovens de leguminosas arbóreas nativas: espécies de Phaseoleae, Sophoreae, Swartzieae e Tephrosieae. Revista Brasileira de Botânica, v.24, n.1, p.85-97, 2001. http://www.scielo.br/pdf/rbb/v24n1/a10v24n1.pdf

OLIVEIRA, E.C. Morfologia de plântulas florestais. In: AGUIAR, I.B.; PIÑA-RODRIGUES, F.C.M. \& FIGLIOLA, M.B. Sementes florestais tropicais. Brasília: ABRATES, 1993. p.175-214.

OLIVEIRA, E.C.; PEREIRA, T.S. Morfologia dos frutos alados em Leguminosae - Caesalpinioideae -
Martiodendron Gleason, Peltophorum (Vogel) Walpers, Sclerolobium Vogel, Tachigalia Aublet e Schizolobium Vogel. Rodriguesia, v.36, n.60, p.35-42, 1984.

RAMOS, M.B.P.;FERRAZ,I.D.K.Estudosmorfológicosde frutos, sementes e plântulas de Enterolobium schomburgkii Benth. (Leguminosae-Mimosoideae). Revista Brasileira de Botânica, v.1, n.2, p.227-235, 2008.http://www.scielo. br/pdf/rbb/v31n2/v31n2a05.pdf

RODERJAN, C.V. Morfologia do estádio juvenil de 24 espécies arbóreas de uma floresta com araucária. Curitiba: UFPR, 1983. 148p. (Dissertação Mestrado).

VIDAL, V.N.; VIDAL, M.R.R. Botânica - Organografia. Viçosa: UFV, 1995. 114p. 